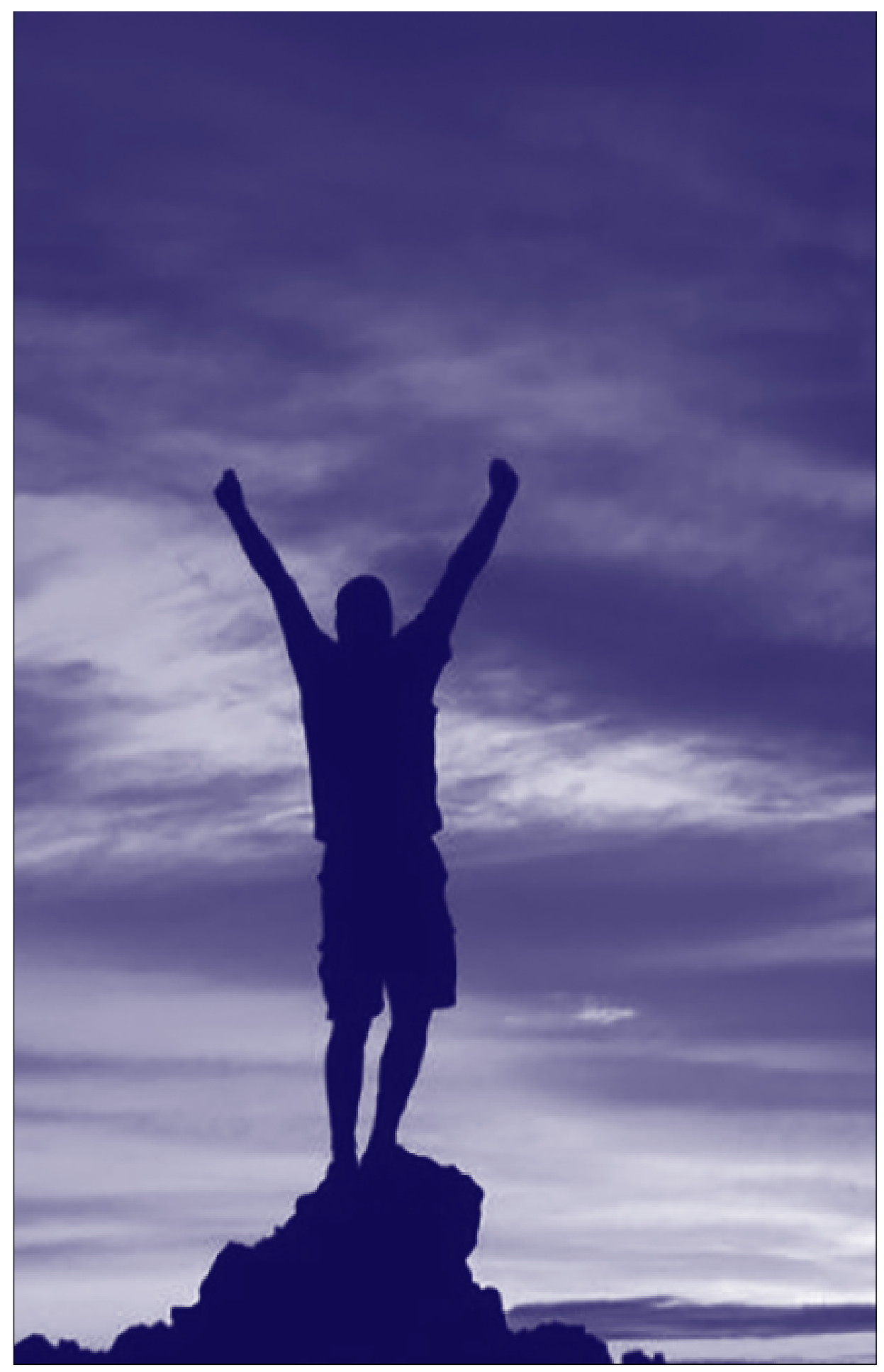




\title{
EL HOMBRE, SER ÉTICO-MORAL
}

\author{
Hno. Antonio Castagnetti Morini, fms
}

\section{El hombre, sujeto de la Teología Moral}

La persona humana es el camino obligado para la fundamentación del juicio ético. El ser humano, creado por Dios, es el fundamento ontológico y objetivo de la Teología Moral de la persona.

Perdida aquella objetividad, dice Ramón Flecha Andrés, autor de varios libros de Teología Moral, se ha buscado afanosamente un criterio para hincar, como en tierra firme, la valoración moral de los comportamientos humanos. La suspicacia ante la verdad objetiva obligaría en los últimos siglos a apelar a una normatividad consensuada por los seres humanos y apoyada por el andamiaje de los ordenamientos legales.

(...) La moral es propia de los seres humanos. La moral es "humana" en múltiples sentidos. Son las personas las que se comportan moralmente. Pero es la moral la que configura la "humanidad". De ahí que haya que afirmar una y otra vez la centralidad de la persona humana en la reflexión moral; y eso, al menos, en dos sentidos inevitables y complementarios: como objetivo de la moralidad: (fr. Ramón Flecha A Moral de la persona).

\section{El hombre: ser consciente y libre}

La libertad humana no puede negarse, siempre que la personal se halle en pleno uso de sus facultades intelectuales y volitivas. Los que, en teoría, la niegan, en la práctica se conducen como si fueran libres, especialmente en casos en que sus derechos y deberes se hallan comprometidos. Ahora bien, considerarse libre es ser responsable de los propios actos, ya que no es posible hacerse responsable de actos compulsivos.

"Desde el punto de vista experimental, dice Brennan, ni las fuerzas físicas ni las biológicas, han demostrado influir de un modo definitivo sobre la libertad humana. Tampoco la compulsión psicológica ha demostrado ser de gran peso en los estudios experimentales efectuados sobre el proceso volitivo. Esto sucedería solamente en el caso en que los valores óptimos nos forzasen a la elección, pero resulta evidente que tanto para el científico como para el ignorante, la voluntad es impulsada frecuentemente por valores de menor importancia. Ante objetos de igual valor podemos experimentar indiferencia e incluso cuando se nos presenta un solo valor y carece- 
mos de alternativas, no se deduce de esto que nos veamos forzados a actuar" (Cfr. R.E. Brennan: Psicología General).

"Ya los salmanticenses comenzaban su estudio de la moralidad afirmando la necesidad y realidad de la libertad humana. La Psicología moderna ha venido a poner de relieve la capacidad de elección del ser humano, su constante-aunque más o menos consciente- orientación hacia un YO ideal, su íntima capacidad de autorrealización. La vida es una serie de elecciones continuadas para el individuo en la que el determinante principal de la elección es la persona como es en sí (incluyendo sus objetivos para sí mismo, su valentía o temor, sus sentimientos de responsabilidad, la fortaleza de su ego o 'fuerza de voluntad'. No podemos considerar ya la persona como 'completamente determinada', entendiendo con ello que está únicamente determinada por fuerzas externas a la persona" (José Ramón Flecha Andrés: Teología moral fundamental).

\section{Limitaciones}

Por otra parte, no es difícil constatar que, en la vida ordinaria, no somos tan libres en nuestras elecciones como suponemos. Muchas de las decisiones que tomamos no son sino la consecuencia de nuestros hábitos, sentimientos, asociaciones, motivaciones basadas en valores sociales o ambientales y, a menudo, influenciadas por el temperamento y otras condiciones biológicas.

Las normas éticas son descritas, a veces, como limitadoras de la libertad, pero esta limitación es más aparente que real. Como observa sabidamente Santo Tomás, el conformarse a las reglas de la recta razón es más bien aumentar nuestra libertad, mientras que apartarse de dichas reglas es caer en la licencia. Las transgresiones de orden moral no suponen evidentemente una perfección de nuestra libertad, sino más bien una imperfección. La libertad total y la coacción determinista se excluyen mutuamente. La solución intermedia entre ambas, parece ser la solución correcta: se da evidentemente la compulsión de la voluntad con cierto valor de condicionamiento, pero se da igualmente la libertad de la voluntad para realizar o no los actos humanos.

\section{Motivación}

En términos generales, tanto los animales como los seres humanos entran en actividad movidos por algún estímulo: atractivo, interés, necesidad, rechazo, etc. La motivación voluntaria, libre e íntimamente ligada a los valores, propia del hombre, es la causa que incita e impulsa a la acción con el fin de alcanzar determinados objetivos los cuales, una vez conseguidos, calman o disminuyen la tensión interior. En todos los casos siempre existe un resorte, una motivación para la acción ¿Por qué lo hacen? 
¿Cuáles son sus motivos? Así, por ejemplo, un soldado se comporta de modo heroico en una batalla y es condecorado; en una calamidad pública un hombre hambriento es capaz de ceder parte de su ración a otra persona más necesitada, una madre se desvela día y noche a la cabecera de su hijo enfermo... otro consagra su vida entera al servicio de Dios como sacerdote, religioso o, siendo laico y casado y profesional, es capaz de consagrar su vida al servicio del prójimo en una misión lejana...

La vida es una interacción constante entre el ser y el medio físico y social en que vive, y las razones que mueven al Yo a comportarse de tal o cual modo, no siempre son claras por lo cual no se puede comprender la motivación como si dependiese de un único factor. En realidad, aunque el factor racional sea siempre el distintivo de toda auténtica motivación intervienen, con mayor o menor peso:

- Las necesidades y urgencias básicas, como son el alimento y el descanso

- Las tendencias

La tendencia, es al mismo tiempo, prontitud en percibir e impulso para obrar de acuerdo a ciertos estímulos seleccionados en forma inconsciente o no bien definidos. La tendencia es una verdadera potencia activa y dinámica y, como tal, constituyente de la motivación. Una tendencia bien orientada ayuda a conseguir fines superiores pero es frecuente que estos fines sean velados ya sea por la oscuridad de la conciencia, en los primeros años, o por errores de percepción, de valoración y, más tarde, por intereses.

- Los hábitos

El hábito es también un componente importante de la motivación. El hábito se compone de un conjunto de patrones, de modos de actuar consistentes y repetidos. Dentro del complejo psicológico que constituye el hábito, algunos pueden adquirir una cierta independencia y subsistir aunque desaparezca el hábito. Los hábitos pueden entrar en conflictos con los intereses personales cuando se trata del cumplimiento de normas éticas y obligaciones. La persona se halla entonces presa de preocupaciones que pueden degenerar en estrés, neurosis de diversos tipos y gravedad que se transforman en serios obstáculos en la realización personal.

- Motivos o móviles

Motivo y tendencia suelen tomarse frecuentemente como sinónimos aunque las diferencias entre ambos sean notorias. En efecto, mientras que la tendencia es más bien innata, el motivo descansa sobre razones lógicas e intereses definidos. 
Los factores o estímulos que mueven al sujeto a la acción pueden ser externos o internos. El estado de necesidad o de urgencia es un verdadero imperativo fisiológico tanto en el animal como en el hombre, urgencia que provoca una actividad encaminada a restablecer el equilibrio (Homeostasis).

Los motivos sociales suelen ser tan importantes como los impulsos básicos o fisiológicos: entre los principales se hallan el responder a otros seres humanos, estar en compañía, adaptarse al ambiente, al grupo; participar, cooperar, ser reconocido socialmente, tener éxito, sentirse útil o necesario.

- Valores

La motivación de la conducta humana se halla directamente vinculada con el sistema de valores personales y sociales. En cada caso la persona se halla más o menos motivada en los campos teorético, económico, estético, social, político o religioso, según describe Spranger en su profundo libro "Los Modos de Vida".

\section{Actitud}

Una actitud es el modo en que una persona está dispuesta a reaccionar frente a un estímulo determinado: persona, objeto material, situación, ideología política, etc... Así por ejemplo si nuestra actitud hacia la Iglesia es favorable, sentimos reverencia cuando nos encontramos en ella, la ayudamos con dinero y en acciones concretas, la defendemos, aceptamos sus programas educativos... Eso no significa que la persona deba estar en continua tensión hacia la Iglesia pero sería fácilmente motivada cuando se presenta la ocasión.

En la actitud se suele considerar:

- la dirección: a favor o en contra,

- la intensidad: grado de confianza con el cual afirmamos o negamos,

- la rapidez con que se reacciona,

- el número de personas involucradas en la actitud: solo o en grupo.

Las actitudes y creencias preparan para la acción, estimulan hacia la consecución de los objetivos deseados, evitan amenazas y defienden al Yo. La actitud resiste, rechaza, evita la información contraria, selecciona las lecturas, los periódicos y los mismos oradores. 


\section{Características}

\section{- Conducta en potencia}

Por sí misma la actitud no es todavía un comportamiento pero en cuanto estructura psíquica abierta al mundo, predispone a comportarse en forma favorable o desfavorable frente al valor apetecido, al ideal asumido con la propia vocación.

\section{- Psiquismo total}

La actitud es la disponibilidad del sujeto, la posibilidad de pasar de la potencia al acto, de la actitud a la realización concreta en la acción. La actitud ético-religiosa es, pues, un proceso lúcido por el cual el creyente, consciente de las creencias asimiladas, de los estímulos, sentimientos, urgencias naturales, conflictos y crisis, lo integra todo en una conducta personal fuertemente motivada y coherente.

\section{- Relación intencional}

La actitud se orienta hacia la consecución de objetivos propios, de los valores conocidos y asumidos por el sujeto.

Esta relación intencional hace especial referencia al factor cognoscitivo el cual no se desliga sino muy difícilmente de la afectividad. La presencia de motivaciones inconscientes dará lugar a actitudes difusas o incoherentes con el valor religioso como sería la búsqueda de protección y seguridad, el deseo secreto de prestigio, de mandar, de gozar de ciertos beneficios y otros fines egoístas inconscientes que usurpan el papel de lo auténtico y verdadero.

\section{- La actitud es cambiante}

Prever futuras conductas, en base a la actitud actual, es siempre riesgoso por no decir imposible. En efecto, la actitud, una vez despertada y desarrollada, no permanece estática o indiferente frente a los nuevos estímulos o sirenas provenientes del ambiente físico y socio-cultural. Por el contrario, el psiquismo, aunque dé la impresión de haber integrado plenamente el valor religioso, es siempre muy sensible al influjo de otros valores motivadores de cambios de actitud por ser portadores de fuentes llamadas hacia otros valores. Es fácil constatar esta característica cambiante de la actitud ya sea en partidos políticos, matrimonios o personas religiosas. 


\section{Acto voluntario}

El análisis del acto voluntario descubre que no es un hecho psíquico simple sino muy complejo. Se trata de un verdadero proceso volitivo en el cual intervienen numerosos factores de orden afectivo e intelectual. En la conciencia del hombre se dan sucesivamente una serie de vivencias que finalmente se resuelven en la ejecución o no ejecución de la acción concreta.

Suele admitirse que la voluntad representa el equilibrio entre los impulsos o tendencias iniciales y primitivas y los motivos dictados por la razón. En ese sentido, la voluntad no sería propiamente la fuerza mental sino el correcto ensamblaje de las fuerzas afectivas e intelectivas en acción.

\section{Opción fundamental}

En un esquema personalista, la primera expresión del comportamiento humano responsable es la opción fundamental. Se trata de una categoría decisiva para la moral. No se puede reducir la moral a la sola opción fundamental de tal manera que resulte una moral de opción fundamental; pero no se puede minusvalorar esta estructura antropológico-moral, ya que es la más importante de todas.

Hablamos de opción fundamental para referirnos no a la decisión del yo periférico, sino a una decisión que brota del centro de la personalidad, del corazón del hombre, como núcleo de su personalidad. Es una decisión fundamental, a favor o en contra de Dios, que condiciona, como intención básica, todos los demás actos.

La opción fundamental se refiere al conjunto de toda la existencia. Es una decisión de tal densidad que abarca totalmente al hom bre, dando orientación y sentido a toda su vida. Es distinta de la elección de objetos comunes, ordinarios o triviales. Es una entrega totalizante: es el "sí" o el "no" de la persona y toda su vida moral debe ser juzgada desde la profundidad de la opción fundamental.

En sentido cristiano y evangélico, la opción fundamental está expresada con el radicalismo neotestamentario: radicalismo ético de Jesús; radicalismo de las parábolas; radicalismo de las formas expresivas de la primitiva comunidad cristiana y, posteriormente en los nuevos discípulos, con fervores de catecúmenos, de recién convertidos o en fervores de novicios.

De ordinario, los actos no pueden expresar todo el valor de la opción fundamental de la vida; para lo cual necesitan tanto de una sucesión repetitiva como de duración en el tiempo, y únicamente el acto de la muerte puede expresar y sellar definitivamente la opción fundamental. Todo acto moral lleva consigo dos aspectos: la particularidad, creada por el horizonte del objeto moral particular y la universalidad en cuanto la opción hace referencia al fin último. 
La opción fundamental es la expresión básica de la moralidad y es a partir de ella que han de ser comprendidas las demás expresiones de la responsabilidad moral. Esta afirmación está de acuerdo con la doctrina de Santo Tomás y de San Agustín sobre el valor moral del fin último.

Con respecto a la opción fundamental surgen algunas preguntas que es necesario tratar de solucionar. Brevemente trataremos de ellas a continuación.

\section{$\checkmark$ Aparición de la opción fundamental}

En la moral tradicional se decía que el niño, en cuanto llega al uso de razón, tiene posibilidad de adherirse al fin último, que no puede ser indiferente al fin último y que no puede dejar de optar a favor o en contra de Dios... De esta afirmación, claramente exagerada, se deducían diversas aplicaciones pastorales en relación al pecado en el niño y la confesión del mismo.

Está claro que estas afirmaciones han de ser matizadas a partir de los estudios y conclusiones de la Psicología porque, si la opción es una decisión total de la persona, solo se podrá dar plenamente cuando el niño haya llegado a una suficiente maduración bio-psico-lógica. Una maduración suficiente se puede colocar solamente al término de la adolescencia.

Esto no quiere decir que, en el niño, no exista responsabilidad alguna. La tiene, pero solamente en cuanto pueda serlo una persona que se está haciendo y que se halla en proceso de hacer su opción fundamental. No se puede pues, considerar al niño como a una persona mayor creyéndole capaz de captar los esquemas morales de los adultos. De aquí surgen varios problemas pastorales: ¿Cómo se ha de plantear pastoralmente el sacramento de la penitencia a los niños y en qué sentido podemos hablar de pecado mortal en esa edad?

En cuanto a la aparición de la opción fundamental, se puede afirmar lo siguiente:

- En un modo normal de crecimiento y desarrollo psicológico, se puede decir que la opción fundamental suele coincidir con la "primera crisis de personalidad" que se da en la adolescencia y que suele coincidir con la crisis psicológica al tomar conciencia del YO personal, claramente individualizado. Ese momento suele coincidir con las crisis religiosa y moral y, por lo mismo, con la posibilidad de afrontar y decidirse frente a la aparición, en su vida, de la opción fundamental.

- Está claro que esta opción fundamental se va preparando desde los primeros años de la niñez; en un ambiente religioso-moral adecuado a la realización de 
actos que van preparando al sujeto para una opción fundamental libre y sin condicionamientos. Solamente en ese sentido los actos del niño han de ser vistos en referencia a la opción fundamental.

\section{$\checkmark$ ¿Cómo se da la opción fundamental?}

La opción fundamental es la decisión por la cual el hombre, plenamente consciente de su acción, dispone voluntariamente y totalmente de sí mismo; determina libre y radicalmente su relación en orden a Dios como último fin. En un momento u otro de la vida puede darse un acto explícito, consciente y voluntario de orientación hacia Dios y su repetición puede darse también en forma implícita.

En una forma u otra esta opción, para ser auténtica, debe ser consciente y libre. Su relación se da de tres modos posibles, a saber:

a. como opción fundamental primera por medio de un acto plenamente consciente;

b. como repetición o refuerzo de la opción fundamental existente y, por último,

c. como cambio o abandono de la opción primera para dar lugar a otra de signo contrario.

\section{Cuestionamientos}

Si es cierto que los actos valen moralmente en tanto que están informados por la opción fundamental, nos podemos preguntar:

- iPuede un pecado comprometer plenamente la opción fundamental?

Dependerá de la esencialidad de dicho acto en la vida cristiana.

- iPuede un solo acto comprometer la opción fundamental?

En un acto plenamente consciente y voluntario, la opción moral queda comprometida; en un acto realizado con menos conciencia y decisión, con dudas y reticencias... es claramente un acto de menor responsabilidad. La opción fundamental permanece pero debilita.

Si admitimos que la opción fundamental es la base de la moral nos preguntamos:

¿Todos los cristianos han hecho la opción fundamental? Si no la han hecho, isu comportamiento es responsable? ¿Qué decir? 
- Hay que desdramatizar el problema. Muchos cristianos no han hecho una opción fundamental explícita; pero se puede hacer de un modo implícito.

- Hay que entender esta cuestión en la línea de los pastoralistas para quienes las comunidades cristianas han ido más "sacramentalizadas" que "evangelizadas".

\section{Responsabilidad del acto moral}

El acto moral es la expresión y manifestación, en cuanto significación y contenido, de la opción fundamental. Desde el punto de vista de la moral dichos actos se dividen en:

a. reflejos como el rotuliano, el parpadeo, la deglución, etc. Propios de la naturaleza biológica del hombre. Como tales, los actos reflejos en ningún caso pueden ser voluntarios y por lo mismo completamente ajenos a toda calificación moral;

b. instintivos que la "Biología define como una pauta hereditaria de comportamiento de carácter universal, con finalidad específica y adaptativa de supervivencia. El instinto es global y compromete a todo el organismo vivo. El instinto es controlable, por lo que no es de respuesta obligatoria".

Tales son, por ejemplo, los instintos de supervivencia, sexual y la voluntad de ganar. Por el hecho de ser controlables, los instintos se hallan sujetos a normas morales que orientan hacia el bien y al fin último.

c. actos rutinarios adquiridos dependientes de la educación recibida en el ambiente socio-cultural. Estos actos no están totalmente privados de libertad, ya que en el transcurso de los años subsiguientes han sido aprobados o reprobados por la persona en forma consciente y libre $y$, de esta manera, subsumidos en la libre realización personal y, desde el punto de vista moral, relativamente responsables por darse entre lo rutinario y lo decisivo;

d. actos humanos. Son aquellos cuyo verdadero dueño es el hombre personal y de los cuales es moralmente responsable. Según la doctrina moral tradicional eso supone de parte del sujeto:

- pleno conocimiento (advertencia y deliberación), y

- decisión personal mediante una actuación de la voluntad libre.

Gravedad moral del acto. Para que un acto pueda considerarse "moralmente grave", además de las dos condiciones fundamentales anotadas en d), el sujeto debe tener conciencia de la gravedad o importancia de la materia y de las consecuencias del acto que realiza (Cfr. M. VIDAL. Moral de la actitud). 